\title{
Within-Individual Change in Arrests in a Sample of Serious Offenders: The Role of Identity
}

\author{
Chongmin $\mathrm{Na}^{1} \cdot$ Ray Paternoster ${ }^{2} \cdot$ Ronet Bachman $^{3}$
}

Received: 29 June 2015 / Revised: 8 October 2015 / Accepted: 22 October 2015 /

Published online: 27 November 2015

(C) Springer International Publishing AG 2015

\begin{abstract}
Objective Paternoster and Bushway (2009) have recently proposed and developed (Bushway and Paternoster 2012, 2013) an identity theory of desistance (ITD). The current study is an initial attempt to empirically examine the tenability of the ITD by assessing whether self-identity and intentional self-change are critically involved in the desistance process among a sample of serious drug-involved adult criminal offenders. Methods Using arrest data from a sample of released prison inmates with non-trivial drug problems and a modified version of conventional random-effects model, we examine the role of a good or favorable identity and pro-social "agentic moves" (Giordano et al. 2002) in period-to period changes in drug use and arrest from the early 1990s until 2008 .

Results The effect of good identity on self-reported drug use remained significant even after controlling for unobserved heterogeneity and other theoretically relevant covariates, whereas its effect on arrest became weaker and statistically non-significant when these covariates were simultaneously considered.

Conclusions While we find only partial support for the ITD, we hope our initial effort to assess the feasibility of the ITD can facilitate further theoretical sophistication and tests of a number of other interesting hypotheses that can address many questions left unanswered in the existing desistance literature.
\end{abstract}

Keywords Desistance $\cdot$ Identity $\cdot$ Turning point

Chongmin $\mathrm{Na}$

cna@jjay.cuny.edu

1 Department of Criminal Justice, John Jay College of Criminal Justice, City University of New York, New York, NY 10019, USA

2 Department of Criminology and Criminal Justice, University of Maryland, College Park, MD 20742, USA

3 Department of Sociology and Criminal Justice, Center for Drug and Alcohol Studies, University of Delaware, Newark, DE 19716, USA 


\section{Introduction}

Since the turn of the twenty-first century, criminology has seen the rise of numerous explanations and theories of desistance from crime, including most prominently (but not exclusively) those by Laub and Sampson [41], ${ }^{1}$ Giordano and colleagues [24, 25], and Maruna $[46,47]$. There is some modest degree of overlap among these, and more than a modest amount between the accounts of Sampson and Laub and Giordano and her colleagues. In both Laub and Sampson's and Giordano and colleagues' explanations, desistance is understood to be due in no small measure to the rehabilitative effect of attachment to previously weak or non-existent social bonds ("turning points" in Laub and Sampson while Giordano et al. refer to these events as "hooks for change"). What drives desistance for Laub and Sampson is primarily a change in the opportunity to commit crime brought about by conventional employment and a quality personal relationship with an intimate partner which brings with it enhanced supervision. ${ }^{2}$ What occurs when one who previously had been free to offend attaches or reattaches to jobs and marriages is that both provide direct social control or monitoring of behavior which reduces the opportunity to commit crimes. While this reconnection with conventional roles is also an important component of Giordano et al.'s desistance theory, they do acknowledge the importance of what they call "upfront work" - critical cognitive and emotional changes that the offender must undergo before these turning points or hooks become salient. Other kinds of individual changes, like a "replacement self" or new identity, occur only after changes in the social bond, what they term "hooks for change."3

More recently, Paternoster and Bushway [17, 18, 52] have proposed a theory of criminal desistance that builds upon previous theories in important ways but extends these views. In their identity theory, offenders have personal identities whereby they think of themselves as one who commits crimes, and this identity is an important source of preferences for certain lines of action (and inaction) - a disinclination to accept conventional (but often low paying, tedious, and restrictive) employment, a general disregard for the feelings and needs of others (self-centeredness), and love of the "party

\footnotetext{
${ }^{1}$ Certainly, the seeds for the 2003 discourse on desistance were planted in the work of Sampson and Laub [58] a decade before this, but we take the 2003 book as containing their initial theory of desistance. This 2003 theory has been subject to a few revisions.

${ }^{2}$ With respect to marriage, they noted that: "[w] hat has not received enough attention is the role that marriage plays in restructuring routine activities and the direct social control that spouses provide.. (p. 135) ... "[p]erhaps the most unexpected finding emerging from the life histories is that marriage may lead to desistance because of the direct social control effects by spouses... along with providing a base of social support, wives took primary control of the planning and management of the household and acted as informal 'guardians' of their husband's activities" ([41]: 136). Employment, too, had its greatest effect not so much on changing who the Glueck boys were as men, but in limiting the opportunities they had to act out: "Work restricts criminal opportunities and thus reduces the probability that criminal propensities will be translated into action ... employers, like wives, can provide direct social control...[i]n other words, employers can keep their employees in line" ([41]: 47).

${ }^{3}$ Giordano et al. [24] stated that "[h]ooks for change can provide an important opening in the direction of a new identity" and "hooks influence the shift in identity" ([24]: 1002). The latter view about temporal order is also consistent with the causal diagram of the theory they offer (fig. 1, p. 1029) wherein identity transformation is a consequence of involvement in conventional roles like parent, spouse, and worker. Further, since emotional transformations involve role taking experiences in pro-social romantic relationships, we would presume that they occur only after exposure to conventional hooks.
} 
life" and use of alcohol/drugs [61]. This working identity of offender and its allied stock of preferences is maintained until a series of failures become linked together and projected into the future such that the offender begins to think of the hardships and disadvantages of a continued life of crime. This "feared self," a fear of what kind of person one may turn out to be (an alone, broken down ex-offender), serves as an initial motivation to change oneself toward one that is more conventional (the "future self"). This movement from the "feared" to the "possible" self brings with it an enhanced positive affect for the self, that one is "finally on the right track." A desire to change is not sufficient, however, because the person, in order to convince others (such as prospective employers and partners) that this effort at self-change is genuine, must take concrete steps in a conventional direction (maintain social distance from crime partners or other drug users, accept part-time or temporary work and its drudgery, get help for drug/alcohol abuse). In the identity theory of desistance, therefore, changes in identity (both with respect to the "feared" and "possible" selves) are the major factors in initiating desistance and turning points or hooks for change are unlikely to arrive or unlikely to be effectively availed until such a change in the self occurs.

In fact, perhaps the single most important distinction among the desistance theories of Laub and Sampson, Giordano and colleagues, and Paternoster and Bushway is the role of, and importance given to, identity transformation. In Laub and Sampson's [41] social control/routine activities framework, identity change has virtually no role to play in desistance except perhaps as a consequence of participation in turning points. Giordano et al. [24] refer to the importance of a "replacement self" in desistance but as in the Sampson/Laub model this identity change occurs only after the actor is involved with conventional roles. Another prominent theory of desistance developed by Maruna [46] places importance on identity in quitting crime, but this theory is premised on identity consistency rather than identity change. ${ }^{4}$ In the Paternoster/ Bushway identity theory, however, a self-change is the moving force in desistance and must occur before other mechanisms like conventional social bonds can ever play a part. It is because one has modified one's identity that explains how turning points or hooks arrive in the first place and why they are only now being taken advantage of. Moreover, in the identity theory of desistance, self-change can occur in the absence of strong conventional bonds. Well-paying manufacturing jobs that were available to the Glueck boys are non-existent for most ex-offenders today [69], and a sporadically employed ex-offender with drug/alcohol issues is unlikely to make a good marriage prospect for a conventional partner [26]. What ex-offenders who desire self-change can do, however, is to cobble together a conventional life (even if a borderline conventional life) from what is available to them - temporary labor pools, occasional construction work, selling one's blood, donations from family and friends, and an intimate partner who may have his/her own history of criminal conduct or drug/alcohol abuse as is on the margins of conventionality. While desistance can take place without a large stock of

\footnotetext{
${ }^{4}$ For Maruna, offenders do not change their identity from an offending antisocial person embedded in a life of crime to one who now sees themselves in a different, conventional light. Rather, offenders who already have pro-social views of themselves in the present deliberately reinterpret their offender-pasts to make previous criminal actions both explicable and consistent with their current favorable views of who they are and what they are "really like." In Maruna's own words ([46]: 154): "[D]esisting is framed as just another adventure consistent with their life-long personality, not as a change of heart. Again, this allows the individual to frame his or her desistance as a case of personality continuity rather than change" (emphasis added).
} 
conventional social bonds, it cannot occur without an intention to change one's identity and preferences.

Even after significant advancement over the past 15 years in theoretical explanations to understand criminal desistance, criminologists still have different views on how desistance is generated or sustained among offenders. ${ }^{5}$ We cannot agree that the issue has been settled - the theoretical gaps are too wide and the empirical evidence too meager to conclude that existing theories have closed the book on what causes some to quit crime. In the desistance literature, explanations for desistance that invoke an offender's identity or change in identity have begun to appear, and we think they hold great promise and ought to be given a chance to see what they can contribute. The identity theory of Paternoster and Bushway [52] is only one form such a theory may take, but this and other identity-based explanations do bring much to the desistance table. Paternoster and Bushway's identity theory provides some explanation as to the antecedent process that initiate desistance processes as offenders link together previously isolated life failures and disappointments, attribute them to the kind of person they are, and project them into the future. The idea of the "feared self" in their theory helps broach the question, "why do many who have been tied to a life of crime for so long, begin to have doubts about the direction of their life?" Their identity theory also offers an explanation as to why conventional structural opportunities like jobs and marriages arrive for some criminal offenders and not others, and why some offenders take advantage of opportunities while others bungle them. This possibility has also been expressed by Bushway and Reuter [19] in their observation that employment was unlikely to lead to desistance in the absence of a personal commitment and deliberate intention to quit crime on the part of the offender, and Giordano et al.'s [25] point that unless a former offender had already committed to change, they would be unmoved by a spouse's effort to supervise and/or restrict their social interactions. Finally, Paternoster and Bushway's $[17,18,52]$ identity theory places human agency, which is expressed through intentional changes in self-identity and preferences consistent with the new identity, at front and center of the desistance. While the theory places large data demands for its verification, small and incremental steps should be taken, however incomplete, and it should be relative easy to disprove.

The identity theory of desistance would seem, therefore, to be a viable alternative to the theories of Laub and Sampson, Giordano and colleagues, and Maruna, and there are a number of interesting hypotheses that can be derived and tested from the theory. Unfortunately, the data demands to comprehensively test the theory are large-longitudinal data with measures of key theoretical constructs such as one's working identity, feared and possible selves, and crystallization of discontent. Before a large-scale study is initiated to fully test all the causal links of the theory, however, it is possible with existing longitudinal data to construct simple hypotheses that will serve the modest purpose of beginning to test the feasibility of parts of the theory. One useful starting point would be to examine whether wave-to-wave temporal changes in key independent variables (personal identity, self-change effort, marriage, employment) have an impact on immediate temporal changes in criminal offending (arrest) and drug use. That is the purpose of this paper. We fully understand that the measures we employ are

\footnotetext{
${ }^{5}$ Criminologists have equally forceful disagreements as to how desistance should be measured or even statistically modeled $[15,16,18]$.
} 
not perfect analogs to the concepts in Paternoster/Bushway's identity theory, and that identity theory contains causal mechanisms that cannot all be tested here, and we are all too aware that a clean causal inference cannot be made. Surely, however, modest tests of new theoretical ideas that show the promise of these ideas are of value to the field, with the promise ultimately leading to more comprehensive and demanding tests of the theory. We attempt the former with the anticipation of contributing to the latter. Based upon the argument presented in the identity theory of desistance, we would hypothesize that:

H1 A good identity should be related to wave-to-wave changes in criminal offending and drug use over time.

H2 Efforts at self-change initiated by a good identity such as entering a drug treatment program for offenders with alcohol and drug issues should be related to wave-to-wave changes in criminal offending and drug use over time.

H3 When self-change efforts and turning points are controlled, the effect of a good identity should diminish since the former are intervening factors and the latter is an antecedent factor to wave-to-wave changes in criminal offending and drug use over time.

H4 When available, tuning points/hooks for change such as a healthy relationship with a pro-social intimate or being employed should be related to wave-to-wave changes in criminal offending and drug use over time.

We will proceed as follows. In the next section, we will briefly review the existing evidence with respect to the identity theory of desistance, and summarize the findings with respect to turning points and cognitive and emotional transformations and desistance. We will then discuss the methodology we used to test the identity theory and acknowledge the weaknesses of any effort like this that uses existing data sets to test hypotheses that the data set was not originally designed to test. We will then present our findings and discuss their theoretical implications in the conclusion of the paper.

\section{Factors Related to Variation in Criminal Offending Over Time}

There is by now a rather extensive empirical literature concerning the factors that are related to variation in offending over time, ${ }^{6}$ so we will present only a brief summary of the most relevant findings for the current paper-those that pertain to well-known "turning points" and identity. Our conclusion from a careful read of this literature is that empirical support for the role of conventional bonds in desistance is present but underwhelming, and one must be careful about what conclusions to draw. Most importantly, the precise causal mechanism involved in desistance remains an area where we are virtually ignorant.

\footnotetext{
${ }^{6}$ For good reviews, see Laub and Sampson [42], Sampson and Laub (2003), Kazemian and Maruna [35], and Giordano et al. [24, 26].
} 
The twin pillars of desistance theory today are marriage and stable employment [41, 24]. In an early study and employing a methodology similar to what we employ, Horney et al. [33] examined month-to-month offending patterns over a period that ranged from 24 to 36 months within a sample of nearly 600 serious male adult offenders released from incarceration. They reported that offending was lower during those months when former offenders were living with their spouses, but that living with an unmarried partner actually increased crime. A similar result was reported by Piquero et al. [54] who reported that among a group of juvenile parolees in California, marriage decreased involvement in crime while a common-law relationship either increased arrests or had a null effect. ${ }^{7}$ With a largely conventional sample (the National Youth Survey), Warr [68] found that marriage did have a crime reducing effect but it was mainly by decreasing the amount of time a person spent with their peers which limited the opportunity for anti-social behavior. This peer effect of marriage was twofold: it "acts to disrupt or dissolve friendship that existed prior to marriage, including relations with other offenders, and accomplices" and it fostered greater involvement with more conventional peers ([68]: 188). Laub et al. [40] employed group-based trajectory modeling to identify four distinct groups of offenders with the sample of Glueck boys now grown into men, two of which clearly evidenced desistance. They found that being married was related to a decline in offending, though not all marriages were the sameearly marriages that gradually built up social control over time were the most important for crime cessation. Later, in Divergent Beginnings, Laub and Sampson [41] found that there was approximately a $30 \%$ reduction in crime over the life-course for those who were married. Revisiting these data with an inverse probability of treatment weighting method, Sampson et al. [59] found that being married was associated with an average $35 \%$ reduction in the odds of crime compared with the hypothetical odds had the man not married though the crime reducing effect of marriage lasted only as long as the man was in the state of marriage. The beneficial marriage effect did not matter if the marital attachment was strong rather than weak nor if the spouse was herself criminal rather than conventional. The relationship between a good marriage and crime reduction over time may not, however, be entirely causal nor uniform.

Skeptics of a large causal "marriage effect" on crime reduction can find some support in an analysis of offending over a 13-year period from a sample of male and female adolescents who had been incarcerated in 1982 conducted by Giordano et al. [24]. They found no relationship either between attachment to spouse or attachment to children and subsequent adult criminal offending. Their follow-up study with the same sample reported in 2007 also failed to find a relationship between marriage and desistance from crime in their quantitative analysis, although in interviews it was found that pro-social partners who provided both a conventional role model for better management of emotions and pro-social definitions were related to quitting crime [26]. Other evidence that the relationship between marriage and desistance from crime may not be causal can be found in a study of Norwegian men by Lyngstad and Skardhammar [45]. Using official data to estimate the propensity of offending both

\footnotetext{
${ }^{7}$ A number of other studies $[62,29,20]$ have found that non-marital romantic relationships may lead to greater involvement in crime, although whether that intimate partner is anti-social or not clearly makes a difference.
} 
5 years before and after marriage, they report that there was a large decrease in crime before the marriage took place (consistent with identity theory).

Using a propensity score matching method to examine the relationship between marriages and offending in the National Youth Survey, King et al. [37] found that selection into marriage was quite large, indicating that entrance into marriage is not largely a matter of chance or luck as Sampson and Laub contended. When selection was controlled, marriage had a weak but significant inverse effect on crime into early adulthood. Further, they also found that while marriage inhibited offending for males, it had no such crime reduction effect for women. Using growth curve models for a sample of nearly 5000 Dutch men and women, Bersani et al. [6] found that being married was associated with a $35 \%$ reduction in the odds of conviction - a marriage effect of comparable magnitude to other studies - but, that the crime inhibiting effect of being in a marriage was nearly twice as high for males compared with females (though still significant). Van Schellen et al. [66] utilized the same Dutch data as Bersani and colleagues and constructed criminal histories for nearly 5000 persons from 12 years old to a maximum age of 70 . For men, they found that marriage was related to a reduction in offending over the life-course, but only when the wife was a non-offender. For women, marriage was associated with desistance regardless of the criminal history of the husband. The importance of the character of the spouse was revealed in the fact that even an unstable marriage to a non-criminal spouse had a crime reduction effect on long-term offending. There is also some evidence that it is not necessarily a good marriage that leads to a reduction in long-term patterns of offending, but a satisfying emotional relationship with a romantic partner (the previously discussed studies by Horney et al. [33] and Piquero et al. [54] exceptions - see also note 3). Recall the study by Giordano et al. $[25,26]$ where they found that pro-social intimate relationships were influential in turning offenders away from crime even when the relationship did not involve marriage.

In a recent meta-review of the literature, Craigg et al. [22] estimated that about two thirds of the published studies examining the "marriage effect" on desistance find a statistically significant effect on subsequent offending. What is also clear, however, is that we do not know the precise causal mechanism involved, whether marriage changes an offender's criminal propensity or merely reduces the opportunity to commit crimes, whether the marriage effect is truly causal or in some large measure spurious due to selection, if the crime reducing effect of marriage, if any, only comes about if the partner is pro-social, and whether or not non-marital romantic partners can also lead someone out of crime. Importantly, we do not have a very good understanding of how pro-social marriage or romantic partners would arrive for offenders, specifically, if there must first be some kind of initial change in an offender's identity that sends a signal that the offender is ready to abandon their involvement in crime and would, therefore, be an attractive partner. In sum, in spite of some contrary evidence, the hypothesis that a good marriage or intimate relationship can lead to desistance from crime cannot be easily dismissed, and any understanding of desistance from crime must consider the role of these factors.

In addition to an intimate social relationship, desistance theorists have almost uniformly spoken of the importance of employment in quitting crime. As with marriage in empirical studies of desistance, however, an "employment effect" has not been consistently strong nor uniformly found. Horney et al. [33], for example, found no 
consistent short-term reduction in offending during months when former prison inmates were employed-property offending was significantly higher during months when former offenders worked but assault was reduced by about an equal measure (though not significant). In an experimental study of recidivism, Uggen [65] found that employment was related to the hazard of arrest within a sample of previously arrested offenders but only among older offenders (those at least 26 years old); employment had no effect on the arrest hazard for younger offenders. In their follow-up to the Glueck boys, Laub and Sampson [41] found that offending was significantly lower during periods of employment, and this was true even with a strong set of controls. Van der Geest et al. [67] examined the effect of employment on adult offending (ages 18 to 32) for a sample of approximately 300 serious offending Dutch youth. After identifying five groups with distinct developmental trajectories, they found that being employed for a full year resulted in a lower conviction rate compared with those who were unemployed for the same period. This crime reduction effect was stronger for high-quality jobs, among those who were hired by an employer rather than through an agency where the job was more likely to be seasonal or temporary, though stability in employment was unrelated to offending. In their study with a high risk sample of Ohio youth, Giordano et al. [24] found that job stability was unrelated to early adult criminal involvement and those with a "full respectability package," which consisted of both being married and having stable employment, were no less likely to offend than others. In their 2007 follow-up study, occupational prestige was unrelated to desistance from crime. With a 7-year follow-up of a sample of male parolees, Piquero et al. [54] found that with the exception of reducing the risk of arrest for violent crimes among whites, full-time work was unrelated to recidivism. Other studies that are careful with the direction of causal inference suggest that desistance from crime precedes employment and other adult roles, findings that resonate more with Paternoster and Bushway's identity theory than the age-graded informal social control theory of Sampson and Laub. For example, Massoglia and Uggen [49] found within a sample of conventional youth that desistance from delinquency had to occur before a successful transition to adult roles like employment could be made. Skardhamar and Savolainen [63] used smoothing spline regression models to identify changes in criminal offending at the time of stable employment. Contrary to the "work induces desistance" argument, but also consistent with the identity theory of desistance, they found that desistance from crime came before the transition to stable work and taking on stable work did not result in a further reduction in crime. They did, however, find that for a very small group (less than $2 \%$ of the sample), legitimate work during active crime periods led to a substantial decline in offending.

There is beginning to appear some empirical evidence in support of the importance of identity in the desistance process. LeBel et al. [43], for example, examined desistance among the 130 male property offenders from the Oxford Recidivism Study who were initially interviewed in the 1990s and were followed up some 10 years later. They found that a previous offender's "subjective states," which included an identity as a conventional family man, was indirectly related to long-term recidivism risk through its effect on reducing re-entry problems. There is evidence in Laub and Sampson's own follow-up of the Glueck boys into old age that is entirely consistent with the identity theory of desistance. They refer ([41]: 142) to the case of Michael who made "a conscious decision" to enter the military because he feared what would happen if he 
did not: "If I'd gone back out on the corner-I'd get mixed up with the same gang that I got involved with, so I didn't want to do that." As Michael attests, he underwent a change of identity and preferences before entering the military. Similar processes are evident in other cases. Norman related that he changed in part because of a feared self (our words, not his) and that "what motivated him in large part was the fear of losing his wife and family if he did not straighten out" (142), and John desisted when he "was ready and willing to take advantage of opportunities that came his way to avoid repeating what he saw as his father's mistakes" (142-143). In all these cases, desistance would not have occurred, it can be argued, without a prior change in the type of person one wanted to be and the actions that were necessary to become that person. Opsal [51] examined the role of both employment and identity in desistance from crime within an interviewed sample of 43 female ex-offenders, with the interviews taken both immediately after the women were released from incarceration and again approximately 3 months later. To summarize the results, Opsal found that both conventional employment and identity change were important in the desistance process though it was impossible to make a clean causal inference as to whether identity change or jobs came first. There was clear evidence from the narratives, however, that the process of desistance involved the ideas of a feared and possible self that are central to the identity theory. One of Opsal's women ([51]: 388) reflects this: "So I got another chance and I'm gonna do it this time, because I want to change. I want to go home and be with my kids. I want to live a drug-free life. I want to be able to be an abiding citizen and do what I need to do and not always be in trouble and be bad-ass. That is not me." The female offenders in Opsal's sample illustrate the difficulties that serious offenders have upon re-entry. All were unable to find the kinds of stable good-paying jobs that the Glueck males enjoyed during a time of economic prosperity. Like virtually all offenders released from prison today, when these women found jobs, they were generally in the food service and janitorial sector, paying at the minimum wage.

Based upon intensive in-person interviews, Stevens [64] explored the relationship between identity and offender rehabilitation in three English prison-based therapeutic communities (TC). She reported that an important component of moving toward desistance was the creation, via participation in the therapeutic community, of a better "possible self." Through participation in TC events, serious offenders learned that they had a stock of valuable and worthwhile skills which led them to think better of themselves and that a life without crime in the future was achievable. The connection between identity change toward a pro-social possible self and quitting crime was vividly expressed by one member of the TC: "Before [TC], I was kind of lost and really broken... I've changed so much. I honestly don't believe I will ever offend again because I'm not that person now. I've found a better person here" ([64]: 540; see also King [38]).

Finally, using longitudinal data (the Rutgers Health and Human Development Project) and growth-curve models, Rocque et al. [57] found that even net of a cluster of control variables, a favorable improvement in one's identity over time was related to a decline in offending. While there has yet to be a definitive study of identity change over time and desistance, these few empirical efforts seem to indicate that one's identity is an important component of the desistance process.

In sum, a number of factors have been suggested to be important in steering former criminal offenders away from crime-turning points like stable jobs and marriages 
most prominently. Although identity has been implicated in the desistance process by various theorists, and placed at center stage in Paternoster and Bushway's theory of desistance, the role of identity change in desistance has not been given as much empirical attention. Bottoms et al. [9] have suggested a theoretical model that integrates both structural factors such as turning points and more agentic or subjective factors in a way similar to Paternoster and Bushway [52]. The identity theory has the advantage of providing specific mechanisms that can be subject to empirical test. While it is true that we cannot in this study test whether identity change is a causal factor that leads to desistance, we do present information about the role of turning points and identity in period-to-period changes in arrest from a sample of over 1000 serious substanceabusing prisoners released from Delaware prisons in the early 1990s whose arrest histories we have recorded until 2008.

\section{Data and Methods}

\section{Sample}

The data for this study came from a longitudinal analysis of serious drug-involved offenders who were released from the State of Delaware correctional system between the years 1990 and 1996. The study was originally designed to examine the effectiveness of a drug therapeutic community (TC), and the sample consisted of 1250 male and female offenders who were randomly assigned to either a control or a treatment condition [34]. Subjects in the original study were first interviewed approximately 9 months prior to release and were re-interviewed at 6, 18, 42, and 60 months after release. Interview information included basic demographics, drug use history, treatment history, living arrangements, sexual behavior and attitudes, physical and mental health indicators, and various attitudinal measures. The sample for the current follow-up consisted of 1044 subjects, of whom $79 \%$ were male and $73 \%$ African-American. ${ }^{8}$ As described below, we obtained arrest history information for a longer follow-up period through 2008. The mean and median age of the sample was 29 when released at their baseline incarceration, while at the end of the follow-up study the mean and median age was 34 .

\section{Measures}

\section{Dependent Variable}

There are two dependent variables used in these analyses. One is the annual number of arrests for each person released. The second is a measure of self-reported drug use. ${ }^{9}$ The number of arrests for each offender that covered the time period from the year of their release from their baseline imprisonment (early to mid-1990s) to 2008 was obtained from the Delaware Statistical Analysis Center, which records all arrests and

\footnotetext{
${ }^{8}$ Because of their very small number of the total $(n=24)$, Hispanic offenders were excluded from our analysis.

${ }^{9}$ The only time self-reported criminal offending was measured was at the first wave post-release and only for one half of the respondents.
} 
imprisonments in the State of Delaware. These data were augmented by arrest data from the National Crime Information Center (NCIC) in order to capture arrests that occurred outside the State of Delaware. ${ }^{10}$ All of these arrests were for new crimes and not for technical violations of parole. From these data sources, we knew both whether someone had been arrested during any given year and the date of the arrest. The frequency of subject's drug use was reported by each offender initially 6 months after release (T1), then at 18-month (T2), 42-month (T3), and 60-month (T4) follow-ups. An ordinal measure of the amount of drug use at each time point ranged from 0 (no drug use) to 6 (use more than once a day). Subjects were asked this question not about all drugs, but about "their drug of choice." The count of annual arrests included a longer post-release time period, but we had a measure of the annual number of exposure days (days the person was not incarcerated) for both dependent variables.

\section{Independent Variables}

While admittedly imperfect, we constructed some measures that reflect each member of our sample's identity and efforts at what we and Kiecolt [36] would call intentional selfchange. ${ }^{11}$ A favorable or good identity was measured with the following six items: (1) All in all, I feel that I am a failure, (2) I feel I do not have much to be proud of, (3) On the whole, I am satisfied with myself, (4) I wish I could have more respect for myself, (5) I certainly feel useless at times, and (6) At times I think that I am no good at all. At each time period when good identity was measured, the factor loadings for all items were 0.57 or higher and the value of Cronbach's alpha ranged from 0.75 to 0.91 . All items except item 3 were reverse coded so that high scores on the good identity measure reflect a positive view of self. While not a measure of criminal/offender identity, a positive identity is nevertheless part of the causal chain that connects self-change with desistance from crime. Further, a similar measure of identity as arrayed along a good-bad dimension was found to be related to desistance in a study of conventional high school-aged youth [57]. With findings reported here, then, we can corroborate the Rocque et al. findings with and older, more seriously offending population, thereby extending the reach of identity theory.

Since these offenders all had a history of drug and/or alcohol use, we also created a measure of intentional self-change based on their seeking help for substance use during each post-release period. A standardized scale of getting drug help was created from three separate items: (1) if the respondent had been in drug treatment during release, (2) the number of days they were in treatment, and (3) if they sought any help from any source for their drug/alcohol problem.

\footnotetext{
${ }^{10}$ The value of multi-state searches for arrest data is revealed by the fact that there were on average two offenses per person that occurred in a state other than Delaware.

${ }^{11}$ Ideally, we would like to have measures of criminal and non-criminal identity or the extent to which persons think of themselves as an offender. Unfortunately, the original researchers did not collect these data. We do, however, have measures of a positive identity, well aware that it is possible for one with a criminal identity to also have a favorable self-image. In addition, as we noted in the introductory paragraphs, movement from a criminal to a conventional identity results in enhance positive affect about one's self, a positive affect which we capture here.
} 
The offenders released from incarceration were not required to participate in drug treatment as a condition of their release, so this measure does capture voluntary movement toward a self-improvement and an additional step toward desistance. In addition, the vast majority of these offenders were returned to the largest city in the state so there was likely to be little variation in the availability of drug treatment programs across persons. Those who really wanted to get help with their drug problem went and got it. This is an additive index meant to capture any intentional activity on the part of the offender to get clean of drugs. At each time period measured, the factor loadings were all 0.60 or higher, and the magnitude of Cronbach's alpha ranged from 0.56 to 0.63 .

We used data from the same after-release interviews to measure traditional "turning points" referred to by Laub and Sampson [41] (and "hooks for change" by [24]). The specific turning points or hooks we measured included whether or not the person was working full or part-time at T1, T2, T3, and T4, which was a binary variable coded 1 for those respondents who selfreported either working full or part-time during each interview. In addition, a binary variable coded 1 was created for those who were married to measure additional major life events the respondents experienced at T1, T2, T3, and T4. A second variable was created to measure the quality of relationship with either a marriage or an intimate partner during the same post-release period, which was coded -1 (if relationship got worse), 0 (if no change), and 1 (if relationship got better). Two additional variables measuring the amount of income during each follow-up that was legal or illegal were created as timevarying covariates.

In addition to these key theoretical variables that are time-varying in nature, we employed a number of control variables that do not vary over time at the between-individual component of the model including respondent's gender (male), race/ethnicity (white), prior arrests (number of arrests before 1990), the age at release for the baseline incarceration, and the treatment status that captures random assignment to one of three drug treatment groups while incarcerated (for more details of these groups, see Inciardi et al. [34])-binary coded with 0 (no treatment) and 1 (one of the three drug treatments). Descriptive statistics for all variables used in the analyses are shown in Table 1.

\section{Analytic Strategy}

\section{Fixed Effects Versus Random Effects Models}

When estimating the impact of within-individual variations in the explanatory variables $\left(x_{i t j}\right)$ on the within-individual variations in the outcome variables of interest $\left(y_{i t}\right)$, researchers have relied on a variety of modeling strategies to account for potential selection biases because unobserved sources of variability across individuals $\left(\alpha_{i}\right)$ may at least partially explain away the observed association between $x_{i t j}$ and $y_{i t}$.

$$
y_{i t}=\beta_{1} x_{i t 1}+\beta_{2} x_{i t 2}+\ldots+\beta_{j} x_{i t j}+\alpha_{i}+\varepsilon_{i t}
$$


Table 1 Descriptive statistics for variables, by wave

\begin{tabular}{|c|c|c|c|c|c|c|c|c|}
\hline & \multicolumn{2}{|c|}{ Wave I } & \multicolumn{2}{|c|}{ Wave II } & \multicolumn{2}{|c|}{ Wave III } & \multicolumn{2}{|c|}{ Wave IV } \\
\hline & Mean & $\mathrm{SD}$ & Mean & $\mathrm{SD}$ & Mean & $\mathrm{SD}$ & Mean & $\mathrm{SD}$ \\
\hline \multicolumn{9}{|l|}{ Time-varying } \\
\hline Arrest & 0.86 & 1.32 & 0.86 & 1.31 & 0.91 & 1.34 & 0.99 & 1.38 \\
\hline Drug use & 1.39 & 1.99 & 2.10 & 2.33 & 2.50 & 2.45 & 2.27 & 2.43 \\
\hline Good identity & 0.00 & 1.00 & 0.00 & 1.00 & 0.00 & 1.00 & 0.00 & 1.00 \\
\hline Get drug help & 0.00 & 1.00 & 0.00 & 1.00 & 0.00 & 1.00 & 0.00 & 1.00 \\
\hline Good identity and get drug help (mean) ${ }^{\mathrm{a}}$ & -0.09 & 0.84 & 0.01 & 0.73 & -0.02 & 0.52 & 0.02 & 0.84 \\
\hline Married $^{\mathrm{b}}$ & 0.08 & 0.27 & 0.10 & 0.31 & 0.15 & 0.36 & 0.14 & 0.34 \\
\hline Relationship better & -0.07 & 0.53 & -0.09 & 0.63 & 0.03 & 0.57 & 0.03 & 0.49 \\
\hline Working $^{\mathrm{b}}$ & 0.62 & 0.49 & 0.49 & 0.50 & 0.41 & 0.49 & 0.42 & 0.49 \\
\hline Friends arrested & 0.21 & 0.41 & 0.23 & 0.42 & 1.75 & 0.43 & 1.80 & 0.40 \\
\hline Legal income & 6.71 & 2.20 & 5.41 & 2.93 & 5.51 & 3.39 & 5.55 & 3.53 \\
\hline Illegal income & 0.05 & 0.22 & 1.40 & 0.86 & 1.34 & 0.84 & 1.27 & 0.77 \\
\hline \multicolumn{9}{|l|}{ Time-invariant } \\
\hline Age at release & 29.62 & 6.93 & & & & & & \\
\hline Male $^{\mathrm{b}}$ & 0.79 & 0.41 & & & & & & \\
\hline White $^{\mathrm{b}}$ & 0.27 & 0.44 & & & & & & \\
\hline Number of prior arrest & 7.11 & 6.29 & & & & & & \\
\hline Treatment $^{\mathrm{b}}$ & 0.73 & 0.44 & & & & & & \\
\hline
\end{tabular}

"Since "good identity" and "get drug help" are standardized scales, the averages of these variables are also presented to describe how these constructs might (or might not) have changed over time

${ }^{\mathrm{b}}$ These variables are binary and the means represent the proportions

Traditionally, two standard solutions have addressed the systematic variation in $\alpha_{i}$ : fixed effects and random effects models $[1,2,32,70]$. The adoption of one approach over the other is often justified based on the accuracy or efficiency of the model in estimating parameters because the choice involves a bias-variance tradeoff. ${ }^{12}$ The Hausman [28] test is often employed to compare the parameter estimates from both models and assess the extent to which bias is introduced by ignoring the correlation between $x_{i t j}$ and $\alpha_{i}$. If we can assume that $\alpha_{i}$ is uncorrelated with one or more of the $x_{i t j}$ in all time periods (i.e., $\alpha_{i}$ is composed entirely of stochastic noise), random effects models are preferred due to its generalizability, flexibility, and efficiency in estimating within- and between-effects as well as cross-level interactions [32, 70]. More commonly, however, $\alpha_{i}$ tends to vary systematically across individuals in the longitudinal panel data and affects within-individual changes in $x_{i t}$ - especially in the desistance research

\footnotetext{
$\overline{{ }^{12}}$ Since fixed effects models estimate $\alpha_{i}$ for each individual to reduce unobserved heterogeneity biases, there is a substantial loss of degrees of freedom ( $N T-N-k$ instead of $N T-k$, where $N$ represents the number of individuals, $T$ represents the number of time periods, and $k$ represents the number of regressors in the equation), which in turn increases the standard errors of the estimators and undermines the model's statistical power to detect a true relationship between variables in the population. On the other hand, random effects models simply estimate the standard deviation of the $\alpha_{i}$ and save many degrees of freedom by assuming a strict exogeneity of $x_{i t j}$, which is often violated yielding inaccurate estimates of parameters.
} 
because individual-specific sources of criminality may predetermine the subsequent changes in a variety of life outcomes [27]. Due to such strict and unrealistic assumptions that can rarely be satisfied, fixed effects models are frequently used as a "default" choice in many disciplines with a brief comment on the Hausman [28] test results, which more often than not testify against random effects models. Some even estimate both models to check whether different approaches produce the same substantive findings regardless of the ways the unobserved heterogeneity is dealt with (e.g., [53]). Indeed, when drawing causal inference about the association between salient life events and offending patterns in the desistance research, unbiasedness is given greater weight than efficiency of the estimators due to the possibility of a substantial amount of bias resulting from selection processes in non-experimental settings $[7,59]$. Considering that $\alpha_{i}$ is often unknown and thus cannot be explicitly measured and included in the model, it makes more sense to use fixed-effects approaches to eliminate the potential confounding by controlling out $\alpha_{i}$, especially in contexts where a true randomized experiment is not feasible and the counterfactual situations should be approximated by the comparison of the outcomes of the same individuals with and without treatment conditions over time.

Our argument is that selection biases result not just from the unobserved timeinvariant sources but from many other time-varying factors not explicitly considered in the model. In particular, criminal desistance involves an on-going process of dynamic interplay between individual's internal and external factors [16]. With the exception of some demographic characteristics (e.g., gender, race) that are time-invariant by definition, most theoretical constructs in the causal diagram of criminal desistance are timevarying in nature, although many of them might have very low variability or remain "relatively stable" over time (e.g., low self-control: [27]). Recent empirical studies suggest that individuals' propensity to commit crime follows more dynamic patterns of development over time than previously conceived by interacting with other social/ environmental factors (e.g., [10, 50]). In this vein, the utility of conventional fixed effects models might be limited in the desistance research if it fails to address more explicitly the dynamic selection biases resulting from unobserved time-varying factors.

In addition to the issues of static and dynamic selection biases originating from the correlation between $x_{i t j}$ and $\alpha_{i}$ or $x_{i t j}$ and $\varepsilon_{i t}$, choice of the model should be determined by the size of within-variation in $x_{i t j}$ relative to the amount of variation in $y_{i t}$ over time. If there is relatively small variation in $x_{i t j}$ over time (especially when there are few time periods), $\alpha_{i}$ will be responsible for the majority of variation in $y_{i t}$. Since the fixed effects models eliminate most of the explanatory power of these "almost" time-invariant covariates that may exist at the between-level, it is hard to observe any significant effect of such within-regressors, and the researchers will have to conclude the analyses with null findings. More importantly, inconsistent results will be generated even in the fixed effects models $[5,55]$ because "the influence of the error on the estimated coefficients becomes larger as the inefficiency of the estimator increases" ([55]: 127). ${ }^{13}$

Another less discussed but still important issue is the limited utility of fixed effects models. Since fixed effects transformation removes all sources of time-invariant

\footnotetext{
${ }^{13}$ Substantively, the fixed effects estimators are highly sensitive to the random error in any given dataset, and thus estimates of the within effects can be overly sample-dependent with the possibility of considerable departure from the true effect due to chance alone (see [21]: 6-7).
} 
heterogeneity (measured or not) before estimating within-effects, the coefficient for any time-invariant regressor cannot be estimated as the values for the time-demeaned $x_{i t j}$ for all $i$ and $t$ are transformed to zero with no variation. In particular, while cross-level interaction has become one of the primary interests in multi-level approaches (e.g., "hierarchical linear model": [56]; "mixed-effects" or "random-coefficient" models: [23]), the fixed effects models do not allow for the test of many interesting hypotheses by explicitly modeling the interaction between time-varying and timeinvariant factors within a unified theoretical framework because the within-between level interaction terms will always have the value of zero in the fixed effects estimation. Lastly, fixed effects models do not perform as intended when we deal with discrete dependent variables such as binary or count events (see [1-4] for more detail).

\section{Random Effects Models with Within-Between Transformations: A Generalized Approach}

The approach we adopt in this study is an alternative solution to the conventional fixed versus random effects approaches, which is gaining popularity in many disciplines as a unified modeling strategy for analyzing longitudinal panel data, but being underutilized by criminologists when they study the determinants of criminal desistance. ${ }^{14}$ It deals nicely with the unobserved heterogeneity bias by rendering the correlation between $x_{i t j}$ and $\alpha_{i}$ irrelevant without sacrificing efficiency by unnecessarily estimating additional parameters and hence inflating the variances of estimators. While much of what might be of substantive interest to the researchers are swept away in the fixed effects models by focusing solely on within-variation, this model keeps all sources of variation in the equation and explicitly models them to retain many benefits of each approach. It requires a slight modification of the conventional random effects models as follows:

$$
y_{i t}=\gamma_{00}+\beta_{j}\left(x_{i t j}-\bar{x}_{i j}\right)+\gamma_{\mathrm{j}} \bar{x}_{i j}+\gamma_{k} z_{i k}+\alpha_{i}+\varepsilon_{i t}
$$

The first step involves averaging the variables over all $T$ time periods for each individual such as $\bar{x}_{i j}=\frac{1}{t} \sum_{t=1}^{t} x_{i t j}$ (between-transformation) and then subtracting $\bar{x}_{i j}$ from $x_{i t j}$ at each time period (within-transformation). The averages of $x_{i t j}\left(\bar{x}_{i j}\right)$ and the time-demeaned $x_{i t j}\left(\bar{x}_{i j}-x_{i t j}\right)$ represent between- and within-individual effects, respectively. If we modify the original random intercept model by replacing the $x_{i t j}$ with these time-demeaned within-variables and adding the averages of $x_{i t}$, completely separated within- and between-effects can be estimated without the violation of the controversial assumption of $\operatorname{Cov}\left(x_{i t}, \alpha_{i}\right)=0$. At the same time, the explanatory power of the model is not limited especially when the roles played by time-invariant or almost time-invariant variables are of particular interest. In particular, this model has a great potential for more advanced analyses of criminal desistance because of its capacity to model cross-

\footnotetext{
${ }^{14}$ Drawing on earlier efforts to address important structural features of data commonly encountered in analyzing clustered data [31, 39, 48], Bryk and Raudenbush [13] first systematically presented this model under the title of hierarchical linear modeling (HLM) as a generalized version of earlier models. Criminologists were quick to respond to this methodological innovation and adopted it to the study of criminal careers with the increasing availability and popularity of longitudinal panel data (e.g., [11, 14, 33, 53]).
} 
level interactions using random coefficient models (RCM: [56]). It is an extension of the previous random intercept models by allowing the within-level coefficients to vary across individuals. By doing so, we can investigate how time-invariant characteristics of individuals shape the effects of time-varying predictors. ${ }^{15}$ Lastly, the current model is more flexible to the distributional assumption in the error terms than the conventional fixed effects models. In desistance research, for example, the outcome variables often involve discrete event counts (e.g., number of arrest, number of self-reported offending). Many of these count variables suffer from "over-dispersion" which necessitates an alternative modeling strategy to the conventional Poisson model by adding an additional parameter that allows for the conditional variance to exceed the conditional mean such as negative binominal regression model [44]. As Allison and Waterman [4] claim, however, fixed effects negative binomial regression models with over-dispersed count dependent variables fail to control out all the time-invariant covariates, measured or not, from the model and thus are not true fixed effects models because they allow for individual-specific variation in the "dispersion" parameter rather than in the conditional mean (see $[3,4]$ for more detail).

\section{Results}

Using both official arrest and self-reported drug use as dependent variables, we present the results of our modified random effects analyses with different model specifications. In the first models (Model 1 in Tables 2 and 3), only the subject's age and the number of days without being incarcerated for each year were used as predictors to estimate the longitudinal patterns of offending over time after controlling for the exposure time. This model specification is widely used under the titles of "growth curve models" within the hierarchical linear modeling (HLM) framework [56] or "latent growth models" within the structural equation modeling (SEM) framework [8]. ${ }^{16}$ In these time-trend only models, the coefficients for the linear trend were positive and significant for both dependent variables (arrest $-\beta=0.016$ or $\operatorname{IRR}=1.017, p<0.001$; drug use $-\beta=0.082, p<0.05$ ), suggesting an increasing pattern of growth with age. The coefficients for the quadratic trend were both negative indicating a deceleration of growth rate over time, although it was only statistically significant for the arrest measure. In sum, contrary to the well-recognized pattern of the age-crime curve that tends to manifest a decreasing slope after a peak during adolescence period [30], the current adult drug offenders, whose mean age was 29.62 when released at the baseline incarceration, continued to commit more crimes until the end of study.

\footnotetext{
${ }^{15}$ For example, the effects of marriage on criminal desistance for serious offenders might be conditional on their ability to adapt to new roles and expectations. If some of them were randomly assigned to rehabilitation programs that provide the knowledge and skills to be successful in their post-release lives, the effects of marriage would vary substantially by the participation in the programs. Thus, the current model allows us to answer not only whether the marriage or treatment works or not separately but also how and why it works. To assess such treatment effect heterogeneity (e.g., differential marriage effects), we can explicitly specify how between-effects moderate the within-effects by creating and adding cross-level interaction terms.

${ }^{16}$ While a variety of time-varying and time-invariant covariates can also be incorporated in these models, the primary interest is to determine the initial level and the shape of growth patterns (e.g., linear, quadratic, or some other non-linear function) and how these growth parameters are affected by other time-varying and timeinvariant covariates.
} 
Table 2 Random effects models predicting official re-arrest

\begin{tabular}{|c|c|c|c|c|c|}
\hline & Model 1 & Model 2 & Model 3 & Model 4 & Model 5 \\
\hline \multicolumn{6}{|l|}{ Within-individual } \\
\hline Age & $1.017 * * *$ & $1.058 * *$ & $1.042 \dagger$ & $1.081 \dagger$ & $1.079 \dagger$ \\
\hline $\mathrm{Age}^{2}$ & $0.995^{* * *}$ & $0.994 * *$ & 0.994 & $0.993 \dagger$ & $0.993 \dagger$ \\
\hline Number of days free & $1.001^{* * *}$ & $1.002 * * *$ & $1.001 * * *$ & $1.002 * * *$ & $1.002 * * *$ \\
\hline Good identity & & $0.910 * *$ & & 0.960 & 0.706 \\
\hline Get drug help & & & $0.919^{*}$ & 0.975 & 0.970 \\
\hline Married & & & & 1.078 & 1.092 \\
\hline Relationship better & & & & 0.917 & 0.914 \\
\hline Working & & & & $0.757 * * *$ & $0.753 * * *$ \\
\hline Friends arrested & & & & 1.004 & 1.006 \\
\hline Income & & & & $1.057 * * *$ & $1.057 * * *$ \\
\hline Illegal income & & & & 1.011 & 1.013 \\
\hline \multicolumn{6}{|l|}{ Between-individual } \\
\hline Age & $1.109 * * *$ & $0.952 \dagger$ & 0.972 & $0.916^{*}$ & $0.913^{*}$ \\
\hline $\mathrm{Age}^{2}$ & $0.998 * * *$ & $0.998 * * *$ & 0.999 & 1.000 & 1.000 \\
\hline Number of days free & $0.999 *$ & $0.999 *$ & $0.998 * * *$ & 0.999 & 0.999 \\
\hline Good identity & & $0.790 * * *$ & & $0.908^{*}$ & $0.912^{*}$ \\
\hline Get drug help & & & 1.000 & 1.050 & 1.048 \\
\hline Married & & & & $0.775 \dagger$ & $0.771 \dagger$ \\
\hline Relationship better & & & & $0.829^{*}$ & $0.828^{*}$ \\
\hline Working & & & & $0.425 * * *$ & $0.425 * * *$ \\
\hline Friends arrested & & & & $0.850 \dagger$ & $0.848 \dagger$ \\
\hline Income & & & & $1.048 * *$ & $1.049 * *$ \\
\hline Illegal income & & & & $1.166^{*}$ & $1.166^{*}$ \\
\hline Age at release & & & & 1.047 & 1.049 \\
\hline Male & & & & 1.127 & 1.114 \\
\hline White & & & & $1.161^{*}$ & $1.158^{*}$ \\
\hline Number of prior arrest & & & & $1.023 * * *$ & $1.024 * * *$ \\
\hline Treatment & & & & $0.826^{*}$ & $0.826^{*}$ \\
\hline \multicolumn{6}{|l|}{ Within-between interaction } \\
\hline $\begin{array}{l}\text { Good identity } \times \text { age at } \\
\text { release }\end{array}$ & & & & & $1.012 \dagger$ \\
\hline Good identity $\times$ male & & & & & 1.117 \\
\hline Good identity $\times$ White & & & & & 1.020 \\
\hline $\begin{array}{l}\text { Good identity } \times \# \text { prior } \\
\text { arrest }\end{array}$ & & & & & $0.988 \dagger$ \\
\hline Good identity $\times$ treatment & & & & & 0.970 \\
\hline Constant & $0.362 * * *$ & $6.295 * * *$ & $5.107 * * *$ & $3.525^{*}$ & $3.77 *$ \\
\hline Observations (individuals) & $\begin{array}{r}n=3866 \\
(1044)\end{array}$ & $\begin{array}{r}n=3866 \\
(1044)\end{array}$ & $\begin{aligned} n= & 2634 \\
& (1032)\end{aligned}$ & $\begin{array}{r}n=2197 \\
(1000)\end{array}$ & $\begin{aligned} n= & 2197 \\
& (1000)\end{aligned}$ \\
\hline
\end{tabular}

${ }^{*} p<0.05, * * p<0.01, * * * p<0.001$ 
Table 3 Random effects models predicting self-reported drug use

\begin{tabular}{|c|c|c|c|c|c|}
\hline & Model 1 & Model 2 & Model 3 & Model 4 & Model 5 \\
\hline \multicolumn{6}{|l|}{ Within-individual } \\
\hline Age & $0.082 *$ & $0.076^{*}$ & $0.061 \dagger$ & 0.004 & 0.001 \\
\hline $\mathrm{Age}^{2}$ & -0.000 & 0.001 & $0.014 * *$ & $0.019 * * *$ & $0.019 * * *$ \\
\hline Number of days free & 0.000 & 0.000 & 0.000 & $0.001 *$ & $0.001 * *$ \\
\hline Good identity & & $-0.349 * * *$ & & $-0.242 * * *$ & -0.091 \\
\hline Get drug help & & & $-0.113^{*}$ & 0.007 & 0.008 \\
\hline Married & & & & 0.180 & 0.191 \\
\hline Relationship better & & & & -0.016 & -0.016 \\
\hline Working & & & & $-0.801 * * *$ & $-0.785 * * *$ \\
\hline Friends arrested & & & & -0.037 & -0.032 \\
\hline Income & & & & $0.060 * *$ & $0.059 * *$ \\
\hline Illegal income & & & & $0.642 * * *$ & $0.637 * * *$ \\
\hline \multicolumn{6}{|l|}{ Between-individual } \\
\hline Age & 0.022 & 0.014 & 0.062 & 0.089 & 0.086 \\
\hline $\mathrm{Age}^{2}$ & -0.000 & -0.001 & $-0.002 *$ & -0.001 & -0.001 \\
\hline Number of days free & -0.001 & -0.001 & $-0.002 *$ & $0.002 *$ & $0.002 *$ \\
\hline Good identity & & $-0.638 * * *$ & & $-0.262 * * *$ & $-0.271 * * *$ \\
\hline Get drug help & & & $-0.605^{* * *}$ & $-0.128 \dagger$ & $-0.130 \dagger$ \\
\hline Married & & & & -0.116 & -0.119 \\
\hline Relationship better & & & & $-0.234 \dagger$ & $-0.231 \dagger$ \\
\hline Working & & & & $-0.676^{* * *}$ & $-0.681 * * *$ \\
\hline Friends arrested & & & & 0.042 & 0.043 \\
\hline Income & & & & -0.028 & -0.027 \\
\hline Illegal income & & & & $1.137 * * *$ & $1.129 * * *$ \\
\hline Age at release & & & & -0.063 & -0.060 \\
\hline Male & & & & $0.209 \dagger$ & $0.220 \dagger$ \\
\hline White & & & & 0.165 & 0.160 \\
\hline Number of prior arrest & & & & -0.003 & -0.003 \\
\hline Treatment & & & & $-0.804 * * *$ & $-0.803 * * *$ \\
\hline \multicolumn{6}{|l|}{ Within-between interaction } \\
\hline $\begin{array}{l}\text { Good identity } \times \text { age at } \\
\text { release }\end{array}$ & & & & & 0.001 \\
\hline Good identity $\times$ male & & & & & $-0.272 \dagger$ \\
\hline Good identity $\times$ White & & & & & 0.156 \\
\hline $\begin{array}{l}\text { Good identity } \times \# \text { prior } \\
\text { arrest }\end{array}$ & & & & & -0.005 \\
\hline Good identity $\times$ treatment & & & & & 0.067 \\
\hline Constant & $2.20 * *$ & $2.26^{* *}$ & $1.77 *$ & 1.022 & 1.030 \\
\hline Observations (individuals) & $\begin{array}{r}n=3250 \\
\quad(1044)\end{array}$ & $\begin{aligned} n= & 3244 \\
& (1044)\end{aligned}$ & $\begin{aligned} n= & 2633 \\
& (1032)\end{aligned}$ & $\begin{aligned} n= & 2196 \\
& (1000)\end{aligned}$ & $\begin{aligned} n= & 2196 \\
& (1000)\end{aligned}$ \\
\hline
\end{tabular}

$* p<.05, * * p<.01, * * * p<.001$ 
In the second models (Model 2 in Tables 2 and 3), we added only the measure of "good identity" - the independent variable of our primary interest - to the first models to assess whether within-individual change in the positive view of self is associated with short-term variation in offending for the same individual above and beyond the effects of time trend and exposure time. Consistent with our theoretical predictions, and our first hypothesis, statistically significant negative relationships were observed between the changes in good identity and the frequency of arrest $(\beta=-0.094$ or IRR $=$ $0.910, p<0.01)$ and drug use $(\beta=-0.349, p<0.001)$, respectively. Specifically, the coefficient $(\beta=-0.094)$ from the negative binomial regression model predicting arrest indicates that a one unit increase in the good identity scale is associated with a $9 \%$ decrease in the number of arrest (i.e., exp $[-0.094]-1=-0.09$ or IRR $-1=-0.09$ ). Consistent with Hypothesis 1, then, having a good identity was significantly related to wave to wave changes in both crime and drug use in a direction consistent with the identity theory.

Our second hypothesis was that efforts at self-help, captured with a measure indicating that the person sought for their substance abuse problem in the postrelease period would be related to wave-to-wave changes in both arrests and drug use. In the third models (Model 3 in Tables 2 and 3), we replicated the second models using "seeking drug help" as a sole predictor for the change in offending after controlling for effects of age and exposure time. This agentic move toward conventional life styles represents that criminogenic identity of drug users has become less satisfying and no longer a locus of commitment. Similar patterns to those observed in the second models were repeated (arrest-IRR $=0.919, p<0.05$; drug use $-\beta=-0.113$, $p<0.05$ ) suggesting that, consistent with Hypothesis 2, effort at self-change by taking concrete steps in a conventional direction might be another critical factor in the process of criminal desistance.

Our third hypothesis predicted that both conventional turning points like successful jobs and marriages as well as acts of intentional self-improvement like seeking help for substance abuse problems would act as intervening variables in between identity change and crime and drug use. If so, controlling for the former set of variables would reduce the relationship between the latter. In the fourth models (Model 4 in Tables 2 and 3), we controlled for both time-varying and time-stable characteristics of individuals to check whether the observed associations between the changes in good identity and offending would disappear when other theoretically relevant covariates are introduced in the models. Specifically, time-varying covariates included other social factors (e.g., marriage, quality of relationship, employment) that are widely employed in the existing literature as important predictors of criminal desistance. Partially consistent with Hypothesis 3, while the direction of the relationship remained the same as in the second model of Table 2 , the effect of good identity on arrest becomes weaker and even statistically non-significant ( $\mathrm{IRR}=0.960, p=0.313$ ) when these covariates were simultaneously considered. Drawing on our theoretical framework [52], we speculated that the changes in these subjective and social factors could mediate the impact of identity shift on arrest, although establishing the causal link between these variables is beyond the scope of the current study. Even in the presence of other covariates, however, the effect of good identity on self-reported drug use remained significant in the predicted direction $(\beta=-0.242, p<0.001)$, suggesting that such subjective changes capturing more dynamic selection processes should be considered seriously in future desistance 
research. Consistent with the findings from existing research and consistent with our Hypothesis 4, within-individual changes in other social factors such as employment status and income level were also significantly associated with changes in arrest and drug use. In particular, having a full- or part-time job was a consistently strong and significant predictor in any model specification, demonstrating its potential as a prosocial "turning point" or conventional "hook for change" in the process of criminal desistance among adult drug-involved offenders (IRR $=0.757, p<0.001$ for arrest; $\beta=$ $-0.801, p<0.001$ for drug use). Interestingly, the beneficial effects of marriage as another widely accepted transformative life event were not detected in the current sample $(\mathrm{IRR}=1.078, p=0.611$ for arrest; $\beta=0.180, p=0.369$ for drug use). As discussed in the previous section, however, many time-varying variables tend to change very slowly (continuous variables) or infrequently (binary or count variables) over the entire study period, and within-estimators may not be suitable for capturing meaningful variation in the dependent variables. Likewise, we suspect that such negligible effects of marriage could result from the small variation of marriage status in this sampleoverall, only $11.3 \%$ of the subjects reported being married across all person-time periods (ranging from 0.08 to 0.15 during wave I-IV) with little variation of marriage status over time. If the effects of marriage take time to appear as investment in the social bond grows, stakes in conformity increase, and self-identity gradually changes from one that characterizes delinquents to one that represents a responsible spouse taking on familial responsibilities [41], the within-effects estimators would fail to capture the whole story and simply suggest that temporal changes in marital status do not have a significant impact on the immediate temporal changes in offending. In these circumstances, however, between-effects of marriage might be strong and statistically significant because the married individuals would commit less crime on average across all waves than their counterparts. ${ }^{17}$ Nonetheless, consistent with Sampson and Laub's [58] position that it is the quality of the marital relationship that matters, those who reported that their intimate relationships were getting better had a lower probability of arrest although it was not significant by conventional criteria $(\mathrm{IRR}=0.917, p=0.178)$.

In the results from the between-individual portion of the models, similar patterns were observed to those of within-effects, although the magnitudes of the relationships were somewhat stronger for the between-effects than within-effects. The fourth models in Tables 2 and 3 show that individuals with better self-identity or who were more employed on average across all time periods were significantly less likely to be arrested (IRR $=0.908, p<0.05 ;$ IRR $=0.425, p<0.001$, respectively $)$ and use drugs $(\beta=-0.262$, $p<0.001 ; \beta=-0.676, p<0.001$, respectively). The between-individual effect of marriage on arrest was relatively strong in the predicted direction although it was only marginally significant (IRR $=0.775, p<0.10)$. It partially supports our previous speculation regarding why the average effect of marriage might be quite large even if we failed to detect any meaningful within-effect of getting married. The average effects of maintaining good intimate relationships on offending were also stronger than its withineffects and even statistically significant for the arrest outcome (IRR $=0.829, p<0.05$ for

\footnotetext{
${ }^{17}$ In this case, while conventional random effects models can detect a strong and significant relationship between marriage and offending, the coefficients of marriage reflect indistinguishably combined effects at both within- and between-levels, which makes them uninterpretable, not to mention the possibility of $\operatorname{Cov}\left(x_{i t j}, \alpha_{i}\right) \neq 0$.
} 
arrest; $\beta=-0.234, p<0.10$ for drug use). For other demographic characteristics, white offenders $(\mathrm{IRR}=1.161, p<0.05)$ and those with more prior arrest histories $(\mathrm{IRR}=1.023$, $p<0.001$ ) were significantly more likely to be arrested, whereas none of these effects were statistically significant for the drug-use outcome. Not surprisingly, treatment group members on average reported a significant reduction of recidivism for both offending measures (IRR $=0.826, p<0.05$ for arrest; $\beta=-0.804, p<0.001$ for drug use).

While the current data failed to yield any statistically significant results, the final models (Model 5 in Tables 2 and 3) hint at some possibility of cross-level interactions in the desistance process. In particular, Table 2 suggests that the crime reduction effects of good identity were more pronounced for those with more prior arrest histories $(\mathrm{IRR}=0.988, p<0.10)$ and less crucial for those who were older at the time of release $(\mathrm{IRR}=1.012, p<0.10)$. Indeed, the offenders with multiple criminal records would be more likely to experience the perception of "feared-self" or "crystallization of discontent" in the face of a package of life failures resulting from frequent involvement with the criminal justice system [52], and accordingly be highly motivated to change than less frequent offenders. Additionally, the effects of the changes in subjective states would be more salient for relatively young or adolescent-limited offenders than for lifecourse persistent offenders who tend to maintain and even expand antisocial behaviors over a longer period of time. Future research should explicitly test other theoretically deduced hypotheses highlighting more dynamic and nuanced interplay between timevarying and time-invariant characteristics of offenders in explaining the process of criminal desistance.

\section{Conclusion}

The current study is an initial attempt to empirically examine only a few of the hypotheses of the identity theory of desistance developed by Paternoster and Bushway $[17,18,52]$ by assessing whether self-identity and intentional self-change are critically involved in the desistance process among a sample of serious drug-involved adult criminal offenders. Our findings suggest that a good identity and intentional efforts at self-improvement (i.e., seeking help for drug problems) might be instrumental in the movement toward a conventional behavioral trajectory as reflected in period-to-period changes in the criminological outcomes. In particular, the effect of good identity on self-reported drug use remained significant even after controlling for other theoretically relevant covariates, whereas its effect on arrest became weaker and statistically nonsignificant when these covariates were simultaneously considered. Our findings thus support two of the key tenets of the identity theory of desistance- that one's identity and making agentic moves like getting help for drug and alcohol abuse are related to the changes in offending outcomes over time. We readily acknowledge that our findings certainly do not confirm identity theory, nor do our measures of identity employed here capture precisely the key theoretical notions of the feared and possible self so integral to the identity theory, and our results could be reconciled with other desistance theories. However, our findings are certainly harmonious with the identity theory of desistance, and suggest an explanation as to why serious offenders without strong pro-social bonds with conventional partners or union-scale jobs, and hampered by drug/alcohol abuse may nevertheless struggle toward leaving their previous life of 
crime. We are quite content with saying that the results we report merely indicate that there is promise in identity theory in explaining some difficult desistance problems.

We also present an analytical approach which has many advantages over conventional approaches but is still under-utilized in studying criminal desistance. We view that the utility of conventional fixed effects approaches is limited in making a true causal influence about "turning points" [41] or "hooks for changes" [24] in desistance research primarily because they, even after controlling for the unobserved sources of individual heterogeneity, do not automatically rule out the rival explanations originating from unobserved confounders that are inherently time-varying in nature (e.g., subjective changes). When such unobserved time-varying characteristics of individuals are closely related to whether or not an individual experiences life transitions and influence subsequent criminality, we cannot say for sure whether turning points or hooks for change are exogenous factors which initiate on-going processes of desistance or rather endogenous conditions which individuals with deliberate motivation to change select into. Bjerk [7] suggests that such dynamic selection processes that are associated with individual choice can potentially be large enough to substantially inflate the true relationship between major life events and criminality. More seriously, he found that more advanced fixed-effects approaches can rather exacerbate such dynamic selection bias and overstate the importance of life events as exogenous factors in explaining criminal desistance. In future desistance research, we are calling for the inclusion of subjective factors capturing more dynamic selection processes in the causal diagram of criminal desistance and time-invariant characteristics or cross-level interaction terms for a more complete explanation of the total variation of dependent variables existing at both within- and between-levels, as well as conditioning effects of withinlevel factors that might vary substantially depending on between-level characteristics. A modified version of random effects models we employed in this study is a useful tool for exploring many untested hypotheses in desistance research while solving various statistical and substantive issues encountered in conventional approaches.

While we think we have at least made a case for continued efforts and refining and testing identity theories of desistance, we are not blind to the many limitations of this study. Two are most glaring. First, identity theory articulates many, complex causal links from the realization of a "feared self" to the crafting of a "possible self" and the demands that come with that new self: changes in preferences and social networks being only two of the most important. The data available to us did not allow us to examine these key causal links; indeed, there is no data set currently available that has measures of all the components of identity theory. A further consequence of this data limitation is that we could not make any clean causal assertion as to whether identity change comes first and then initiates changes in preferences and social networks. Additionally, the validity of the theory's other propositions (such as how the offenders make initial moves to change their identity or whether offenders undergoing internal changes in identity and preferences are more receptive to the pro-social turning points or hooks for change) are still left unverified.

However, in this sample of criminal offenders with long arrest histories, and little in the way of opportunities for pro-social jobs and marriages upon release (a very weak, virtually non-existent "respectability package" [24]), a favorable identity and "agentic move" toward getting help with their substance abuse problems were both related to declines in arrest over time. It is encouraging that many of the drug offenders took an 
active role in reshaping their criminal careers as purposive, intentional decision-makers even in the absence of exogenously generated social factors they do not always have control over. Our findings suggest that such subjective changes and agentic moves indeed have potential to produce a downward deflection in a previous offender's offending pattern, in some instances net of other important social factors. This speaks directly to a weakness of existing desistance theories alluded to earlier in the paperboth Sampson and Laub's and Giordano and colleagues' theories are very structural and socially deterministic, giving very little power for intentional self-chance, which we take to be a central element of human agency. In the age-graded theory, people do not act; they simply react to the demands for social control required by the role they are in. Since "desistance by default" is given such a prominent position in the theory, there is little in the way of offenders taking on the task of intentionally changing themselves (2003: 278). While Giordano and colleagues do acknowledge the importance of what they call "upfront work," they are clear in the 2002 paper and double down in the 2007 paper on the premise that desistance comes about not by the actions of individuals or because of "individualistic mental processes" ([26]: 1607) but rather through participation in more conventional social relationships and the emotional changes they bring. We are of the opinion that desistance and life-course theories generally have been riding the structural horse for too long and serious theoretical (and empirical) work on how human agency informs and is reflected in the desistance process is long overdue.

We think this study clears an important first hurdle for any new theoretical system - does it appear to explain? Not explain everything, nor explain with perfect precision, but does it seem to hold promise for the field? Our study supports other emerging studies in the literature both qualitative [12, 38, 51, 60, 64] and quantitative $[43,57]$ which point to the fact that one's identity (and identity change) is related to desistance.

Finally, the twisted history of criminal justice policy recommendations based on a few studies (e.g., should we arrest or otherwise handle those accused of domestic violence?) has made us a bit gun-shy about what this study says about criminal justice policy and programs. However, considering that it is very unlikely that legitimate, "living wage" employment and conventional marriages are unlikely to occur for today's serious drug-involved offenders - many of whom are disadvantaged minorities who are returned to communities characterized by concentrated disadvantage - our findings offer more optimistic views than existing theoretical accounts of how desistance occurs. Even without the "full respectability package" of union jobs, GI Bills, and conventional marriages, offenders can, if they want and decide to and turn away from who and what they once were, cobble together a life that does not include crime and life-wrecking drug use. Life "on the margins of conventionality" is what most of our desisting offenders were able to achieve with the help of changes in what they thought about themselves and initial, concrete steps to get help with their drug and alcohol problems. While the essence of our argument is that intentions and self-change are important in desistance, our position is not that "offenders can change if only they want to," nor is it meant to minimize the cumulative obstacles and impediments that even the best intentioned offenders can face when released from incarceration. Further, while we have not followed these offenders out to their death, the efforts that some have taken to avoid crime in the short-term seems to have paid off. We hope our initial effort to assess the feasibility of the identity theory of desistance can facilitate further theoretical 
sophistication and tests of a number of other interesting hypotheses that can address many questions left unanswered in the existing desistance literature.

\section{References}

1. Allison, P. D. (2005). Fixed effects regression methods for longitudinal data using SAS. Cary: The SAS Institute.

2. Allison, P. D. (2009). Fixed effects regression methods. Thousand Oaks: Sage Publications.

3. Allison, P. D. (2012). Beware of software for fixed effects negative binomial regression. Downloadable at http://www.statisticalhorizons.com/fe-nbreg.

4. Allison, P. D., \& Waterman, R. (2002). In R. M. Stolzenberg (Ed.), Socological methodology 2002. Oxford: Basil Blackwell.

5. Beck, N. L. (2001). Time-series cross-section data: what have we learned in the past few years? Annual Review of Political Science, 4, 271-93.

6. Bersani, B. E., Laub, J. H., \& Nieuwbeerta, P. (2009). Marriage and desistance from crime in the Netherlands: do gender and socio-historical context matter? Journal of Quantitative Criminology, 25, $3-24$.

7. Bjerk, D. (2009). How much can we trust causal interpretations of fixed-effects estimators in the context of criminality? Journal of Quantitative Criminology, 25, 391-417.

8. Bollen, K. A., \& Curran, P. J. (2006). Latent curve models: a structural equation perspective. Hoboken: Wiley.

9. Bottoms, A., Shapland, J., Costello, A., Holmes, D., \& Muir, G. (2004). Towards desistance: theoretical underpinnings for an empirical study. The Howard Journal, 43, 368-389.

10. Burt, C. H., Simons, R. L., \& Simons, L. G. (2006). A longitudinal test of the effects of parenting and the stability of self-control: negative evidence for the general theory of crime. Criminology, 44, 353-396.

11. Brame, R., Bushway, S., \& Paternoster, R. (1999). On the use of panel research designs and random effects models to investigate static and dynamic theories of criminal offending. Criminology, 37, 599-641.

12. Breen, A. V. (2014). Changing behavior and changing personal identity: the case of pregnant and parenting young women and antisocial behavior. Identity: An International Journal of Theory and Research, 14, 60-79.

13. Bryk, A. S., \& Raudenbush, S. W. (1992). Hierarchical Linear Models: Applications and Data Methods. Newbury Park, CA: Sage.

14. Bushway, S., Brame, R., \& Paternoster, R. (1999). Assessing stability and change in criminal offending: a comparison of random effects, semi-parametric, and fixed effects modeling strategies. Journal of Quantitative Criminology, 15, 23-61.

15. Bushway, S. D., Piquero, A., Brody, L. M., Cauffman, E., \& Mazerolle, P. (2001). An empirical framework for studying desistance as a process. Criminology, 39, 491-513.

16. Bushway, S. D., Thornberry, T. P., \& Krohn, M. D. (2003). Desistance as a developmental process: a comparison of static and dynamic approaches. Journal of Quantitative Criminology, 19, 129-153.

17. Bushway, S. D., \& Paternoster, R. (2013). Desistance from crime: a review and ideas for moving forward. In C. L. Gibson \& M. D. Krohn (Eds.), Handbook of life-course criminology (pp. 213-231). New York: Springer.

18. Bushway, S. D., \& Paternoster, R. (2012). Understanding desistance: theory testing with formal empirical models. In Measuring crime and criminality: advances in criminological theory (vol. 17), edited by John MacDonald. New Brunswick, NJ: Transaction Publishers.

19. Bushway, S. D., \& Reuter, P. (1997). Labor markets and crime risk factors. Pp. in Lawrence Sherman (Eds.), Preventing crime: what works, what doesn't, what's promising.

20. Capaldi, D. M., Kim, H. K., \& Owen, L. D. (2008). Romantic partners' influence on men's likelihood of arrest in early adulthood. Criminology, 46, 269-299.

21. Clark, T. S., \& Linzer, D. A. (2012). Should I use fixed or random effects? Emory University. Available at http://polmeth.wustl.edu/mediaDetail.php?docId=1315.

22. Craigg, J. M., Diamond, B., \& Piquero, A. R. (2014). Marriage as an intervention in the lives of criminal offenders. In J. A. Humphrey \& P. Cordella (Eds.), Effective interventions in the lives of criminal offenders. New York: Springer.

23. Fitzmaurice, G. M., Laird, N. M., \& Ware, J. H. (2004). Applied Longitudinal Analysis. New York: Wiley. 
24. Giordano, P. C., Cernkovich, S. A., \& Rudolph, J. L. (2002). Gender, crime, and desistance: toward a theory of cognitive transformation. American Journal of Sociology, 107, 990-1164.

25. Giordano, P. C., Cernkovich, S. A., \& Holland, D. D. (2003). Changes in friendship relations over the life course: implications for desistance from crime. Criminology, 41, 293-327.

26. Giordano, P. C., Schroeder, R. D., \& Cernkovich, S. A. (2007). Emotions and crime over the life-course: a neo-Median perspective on criminal continuity and change. American Journal of Sociology, 112, 1603-1661.

27. Gottfredson, M. R., \& Hirschi, T. (1990). A general theory of crime. Stanford: Stanford University Press.

28. Hausman, J. A. (1978). Specification tests in econometrics. Econometrica, 46, 1251-71.

29. Haynie, D., Giordano, P., Manning, W., \& Longmore, M. (2005). Gender, romance, and delinquent involvement. Criminology, 43, 177-210.

30. Hirschi, T., \& Gottfredson, M. R. (1983). Age and the explanation of crime. American Journal of Sociology, 89, 552-584.

31. Hsiao, C. (1986). Analysis of Panel Data. New York: Cambridge University Press.

32. Hsiao, C. (2003). Analysis of panel data. New York: Cambridge University Press.

33. Horney, J., Osgood, D. W., \& Marshall, I. H. (1995). Criminal careers in the short-term: intra-individual variability in crime and its relation to local life circumstances. American Sociological Review, 60, 655-673.

34. Inciardi, J. A., Martin, S. S., \& Butzin, C. A. (2004). Five-year outcomes of therapeutic community treatment of drug involved offenders after release from prison. Crime and Delinquency, 50, 88-107.

35. Kazemian, L., \& Maruna, S. (2009). Desistance from crime. In M. D. Krohn, A. J. Lizotte, \& G. P. Hall (Eds.), Handbook on crime and deviance (pp. 277-295). New York: Springer.

36. Kiecolt, K. J. (1994). Stress and the decision to change oneself: a theoretical model. Social Psychology Quarterly, 57, 49-63.

37. King, R. D., Massoglia, M., \& Macmillan, R. (2007). The context of marriage and crime: gender, the propensity to marry, and offending in early adulthood. Criminology, 45, 33-66.

38. King, S. (2013). Early desistance narratives: a qualitative analysis of probationers' transitions towards desistance. Punishment and Society, 15, 147-165.

39. Laird, N. M., \& Ware, H. (1982). Random-effects models for longitudinal data. Biometrics, 38, $963-974$.

40. Laub, J. H., Nagin, D. S., \& Sampson, R. J. (1998). Trajectories of change in criminal offending: good marriages and the desistance process. American Sociological Review, 63, 225-238.

41. Laub, J. H., \& Sampson, R. J. (2003). Shared beginnings, divergent lives: delinquent boys to age 70. Cambridge: Harvard University Press.

42. Laub, J. H., \& Sampson, R. J. (2001). Understanding desistance from crime. In M. Tonry (Ed.), Crime and justice: an annual review of research. 28 (pp. 1-69). Chicago: University of Chicago Press.

43. LeBel, T. P., Burnett, R., Maruna, S., \& Bushway, S. (2008). The "chicken and egg" of subjective and social factors in desistance from crime. European Journal of Criminology, 5, 131-159.

44. Long, S. (1997). Regression models for categorical and limited dependent variables. Thousand Oaks: Sage Publications, Inc.

45. Lyngstad, T. H., \& Skardhamar, T. (2013). Changes in criminal offending around the time of marriage. Journal of Research in Crime and Delinquency, 50, 608-615.

46. Maruna, S. (2001). Making good: how ex-convicts reform and build their lives. Washington, D.C.: American Psychological Association Books.

47. Maruna, S. (2004). Desistance and explanatory style: a new direction in the psychology of reform. Journal of Contemporary Criminal Justice, 20, 184-200.

48. Mason, W. M., Wong, G. M., \& Entwistle, B. (1983). Contextual analysis through the multilevel linear model. In S. Leinhardt (Ed.), Sociological methodology (pp. 72-103). San Francisco: Jossey-Bass.

49. Massoglia, M., \& Uggen, C. (2010). Settling down and aging out: toward an interactionist theory of desistance and the transition to adulthood. American Journal of Sociology, 116, 543-582.

50. Na, C., \& Paternoster, R. (2012). Can self-control change substantially over time?: Rethinking the relationship between self and social control. Criminology, 50, 427-462.

51. Opsal, T. (2012). "Livin' on the straights": identity, desistance, and work among women post-incarceration. Sociological Inquiry, 82, 378-403.

52. Paternoster, R., \& Bushway, S. (2009). Desistance and the feared self: toward an identity theory of desistance. Journal of Criminal Law and Criminology, 99, 1103-1156.

53. Paternoster, R., Bushway, S., Brame, R., \& Apel, R. (2003). The effect of teenage employment on delinquency and problem behaviors. Social Forces, 81, 297-335.

54. Piquero, A. R., MacDonald, J., \& Parker, K. (2002). Race, local life circumstances, and crime. Social Science Quarterly, 83, 654-670. 
55. Plumper, T., \& Troeger, V. E. (2007). Efficient estimation of time-invariant and rarely changing variables in finite sample panel analyses with unit fixed effects. Political Analysis, 15, 124-39.

56. Raudenbush, S. W., \& Bryk, A. S. (2002). Hierarchical linear models. Thousand Oaks: Sage.

57. Rocque, M., Posick, C., \& Paternoster, R. (2014). Identities through time: an exploration of identity change as a cause of desistance. Justice Quarterly (forthcoming).

58. Sampson, R. J., \& Laub, J. H. (1993). Crime in the making: pathways and turning points through life. Cambridge: Harvard University Press.

59. Sampson, R. J., Laub, J. H., \& Wimer, C. (2006). Does marriage reduce crime? A counter-factual approach to within-individual causal effects. Criminology, 44, 465-508.

60. Sarpe, G. (2015). Precarious identities: 'young' motherhood, desistance and stigma. Criminology and Criminal Justice. Available at http://crj.sagepub.com/content/early/2015/02/13/ 1748895815572163.abstract

61. Shover, N. (1996). Great pretenders: pursuits and careers of persistent thieves. Boulder: Westview Press.

62. Simons, R. L., Stewart, E., Gordon, L. C., Conger, R. D., \& Elder, G. H. (2002). A test of life-course explanations for stability and change in antisocial behavior from adolescence to young adulthood. Criminology, 40, 401-434.

63. Skardhamar, T., \& Savolainen, J. (2014). Changes in criminal offending around the time of job entry: a study of employment and desistance. Criminology, 52, 263-291.

64. Stevens, A. (2012). I am the person now I was always meant to be: identity reconstruction and narrative reframing in therapeutic community prisons. Criminology and Criminal Justice, 12, 527-547.

65. Uggen, C. (2000). Work as a turning point in the life-course of criminals: a duration model of age, employment, and recidivism. American Sociological Review, 65, 529-46.

66. Van Shellen, M., Apel, R., \& Nieuwbeerta, P. (2012). “Because you're mine, I walk the line?” Marriage, spousal criminality, and criminal offending over the life-course. Journal of Quantitative Criminology, 28, 701-723.

67. Van der, G., Victor, R., Catrien, C., Bijleveld, J. H., \& Blokland, A. A. (2011). The effects of employment on longitudinal trajectories of offending: a follow-up of high-risk youth form 18 to 32 years of age. Criminology, 49, 1195-1234.

68. Warr, M. (1998). Life-course transitions and desistance from crime. Criminology, 36, 183-215.

69. Wilson, W. J. (1997). When work disappears: the world of the new working poor. New York: Vintage.

70. Wooldridge, J. M. (2002). Econometric analysis of cross section and panel data. Cambridge: MIT Press. 